УДК 556.3:631.6.03(470.61)

ПРОБЛЕМЫ ХОЗЯЙСТВЕННО-ПИТЬЕВОГО ВОДОСНАБЖЕНИЯ НАСЕЛЕНИЯ ЮГА РОССИИ НА ПРИМЕРЕ САЛЬСКОГО РАЙОНА РОСТОВСКОЙ ОБЛАСТИ

\author{
Харчук В.В., Тарасов М.Г.
}

ФГБОУ ВО «Южный федеральный университет», Институт наук о Земле, Ростов-на-Дону, e-mail:Kharchvv@mail.ru

Статья посвящена изучению гидрогеологических особенностей юго-восточной части Ростовской области для решения проблемы хозяйственно-питьевого водоснабжения. В качестве примера рассмотрен Сальский район - один из важных производителей растениеводческой и животноводческой продукции в Российской Федерации. Актуальность темы исследований обосновывается острой нехваткой питьевых вод, соответствующих санитарным нормам, как в Сальском районе, так и в европейской части юга России в целом. Климатические особенности региона, повышенная минерализация, высокий уровень загрязнения поверхностных вод, значительное содержание органических веществ в породах, ограничивающих использование данных вод для хозяйственно-питьевого водоснабжения. На сегодняшний день сложилась ситуация, когда произошли существенные изменения гидрогеологических условий изучаемой территории, вышли сроки утверждения запасов для всех месторождений подземных вод, а реконструкция и расширение внешнего водоснабжения не представляется возможной в силу экономических причин. На основании фондовых материалов и выполненных полевых и лабораторных исследований выявлен наиболее перспективный для решения проблемы водоснабжения водоносный горизонт, а именно, конкско-караганский. Приводится краткая характеристика его гидрогеологических, гидрогеохимических и др. параметров. Для Сальского месторождения рассчитаны эксплуатационные запасы, а для района - прогнозные ресурсы подземных вод конкско-караганского водоносного горизонта; определена максимально возможная производительность проектируемого водозаборного сооружения. Показано, что альтернативой реконструкции и расширению внешнего водоснабжения является введение в эксплуатацию нового водозаборного сооружения, которое будет экономически более рентабельным.

Ключевые слова: водоносный горизонт, месторождение подземных вод, водозабор, эксплуатационные запасы, подземные воды, водоснабжение

\title{
PROBLEMS OF THE PUBLIC WATER SUPPLY FOR THE POPULATION IN THE SOUTH OF RUSSIA USING THE EXAMPLE OF SALSK DISTRICT IN ROSTOV REGION
}

\author{
Kharchuk V.V., Tarasov M.G. \\ Federal State Budget-Funded Educational Institution of Higher Education Southern Federal University, \\ Institute of Earth Sciences, Rostov-on-Don, e-mail: Kharchvv@mail.ru
}

\begin{abstract}
The article is concerned with the study of hydrogeological features in the South Eastern part of Rostov Region to solve the problem of the public water supply. Salsk Distric, one of the important producers of crop and livestock products in the Russian Federation, is considered as an example. The relevance of the research topic is justified by the acute shortage of drinking waters that comply with the sanitary standards both in Salsk District and in the European part of the South of Russia, as a whole. The climatic features of the region, high salinity, high level of pollution of surface waters, significant content of organic substances in rocks, restrict the ability to search for waters of the appropriate quality. Currently, there is a situation where there have been significant changes in the hydrogeological conditions of the study area, the time to approve reserves for all the groundwater deposits is up, and reconstruction and expansion of external water supply is impossible for economic reasons. On the basis of the archive materials and field researches done, the most promising aquifer, namely Konksk-Karagan, was identified to solve the water supply problem. A brief description of its hydrogeological, hydrogeochemical and other parameters is given. The predicted resources for Salsk deposit are calculated, and the groundwater storage of Konksk-Karagan aquifer is estimated for the region; the maximum capacity of the water intake structure projected is determined. It is shown that commissioning of a new water intake structure is alternative to reconstruction and expansion of external water supply, the former being economically more cost-effective.
\end{abstract}

Keywords: aquifer, groundwater deposit, water intake, storage, groundwater, water supply

Поиск, разведка и оценка запасов пресных подземных вод для питьевого и хозяйственного водоснабжения остается одной из самых острых проблем современности. Особую актуальность она приобретает для районов атлантико-континентальной европейской (степной области) умеренного пояса Российской Федерации (Б.П. Алисов). На территориях, приуроченных к обозначен- ному району, наблюдаются засухи (очень сильные повторяются 1-2 раза в 10 лет); низкое годовое количество осадков, небольшая высота снежного покрова, значительное влияние суховеев. Перечисленные климатические особенности формируют условия недостаточного увлажнения, которые характерны для Сальского района Ростовской области. 
Потребность г. Сальска в воде хозяйственно-питьевого назначения по расчетам ОАО «Института «Южводпроект», составляет 20,5 тыс. м³/сут. Перспективная потребность не определялась из-за спада городской экономики. В настоящее время для решения вопроса водоснабжения г. Сальска эксплуатируется конкско-караганский водоносный горизонт, в пределах которого в разные годы разведаны 3 месторождения подземных вод: Сальское (1962-1963 гг.), Гигантовское (1972 г.) и Новосальское (1975 г.). По сложности гидрогеологических условий месторождения подземных вод соответствуют I группе [1]. По всем месторождениям был произведен подсчет эксплуатационных запасов по категориям А и В, утвержденные в ТКЗ ВДТГУ СССР: по Сальскому МПВ - 1965 г., по Гигантовскому - 1972 г., по Новосальскому - 1975 г [2, 3]. Последние два месторождения с момента утверждения запасов и по настоящее время не эксплуатируются.

За прошедшие годы отмечается существенное изменение водохозяйственной обстановки в Сальском районе, например эксплуатация сальских групповых водозаборов привела к формированию депрессионной воронки. Кроме того, истекли сроки утверждения запасов для всех месторождений подземных вод, а возможность реализации проекта реконструкции и расширения внешнего водоснабжения населенных пунктов района по-прежнему отсутствует. Все перечисленные причины предопределили необходимость выполнения новых гидрогеологических работ и проведение оценки соответствия режима эксплуатации ранее выполненным прогнозам.

Цели статьи:

1) на основании полученной информации о повторном исследовании водоносных горизонтов территории выделить наиболее перспективный из них для удовлетворения потребности населения Сальского района Ростовской области в водных ресурсах;

2) подтвердить ранее проведенную оценку обеспеченности на расчетный период и потенциальных резервов эксплуатационных запасов конкско-караганского водоносного горизонта Сальского месторождения, используемого в настоящее время для хозяйственно-питьевого водоснабжения;

3) определить максимально возможную производительность проектируемого водозаборного сооружения, введение в эксплуатацию которого позволит полностью обе- спечить населенные пункты района водой необходимого качества.

\section{Геологические и гидрогеологические условия Сальского района Ростовской области}

Район исследований расположен на Сальском поперечном поднятии и Целинской седловине [4], которые являются северными окраинными тектоническими элементами Азово-Кубанской впадины и Ставропольского поднятия. Фундамент в пределах указанных структур сложен дислоцированными породами каменноугольного возраста, а чехол - меловыми, палеогеновыми и неоген-четвертичными отложениями. В геоморфологическом отношении изучаемая территория находится в северо-восточной части Азово-Кубанской аккумулятивной равнины [5], расположенной в западной части Предкавказья.

Гидрографическая сеть Сальского района представлена р. Средний Егорлык (левый приток р. Западный Маныч). Водосборная площадь бассейна составляет 2270 км², общая длина реки - 187 км. Питание ее происходит главным образом за счет атмосферных осадков, а также за счет талых вод. Скорость течения воды колеблется от 0,11 до $1,31 \mathrm{~m} / \mathrm{c}$, расход - от 0,025 до $0,85 \mathrm{~m}^{3} / \mathrm{c}$ [6]. Поверхностные воды р. Средний Егорлык отличаются повышенной минерализацией. На водомерном посту у с. Шаблиевка величина ее колеблется от 0,7-1,5 г/дм³; в многоводное половодье повышается до 4,5 г/ дм $^{3}$; в маловодье и в меженный период 5,0-6,0 г/дм ${ }^{3}$ [7]. На р. Средний Егорлык имеются два водохранилища: Сальское, остаточным стоком которого наполняется Воронцовско-Николаевское водохранилище. Воды Сальского водохранилища используются для орошения.

Основные черты гидрогеологических условий Сальского района в большей степени определяются наличием и характером водоносных горизонтов, развитых в породах, слагающих его территорию [8]. В пределах четвертичных отложений выделены следующие водоносные горизонты:

- верхнечетвертичных и современных аллювиальных и аллювиально-делювиальных отложений $\left(a, a d Q_{I I-I V}\right)$;

- нижне-, средне- и верхнечетвертичных аллювиально-морских отложений $\left(\operatorname{am} Q_{I-I I I}\right)$;

- нижне-, средне- и верхнечетвертичных эолово-делювиальных и делювиальных отложений $\left(v d, d Q_{I-I I I}\right)$. 


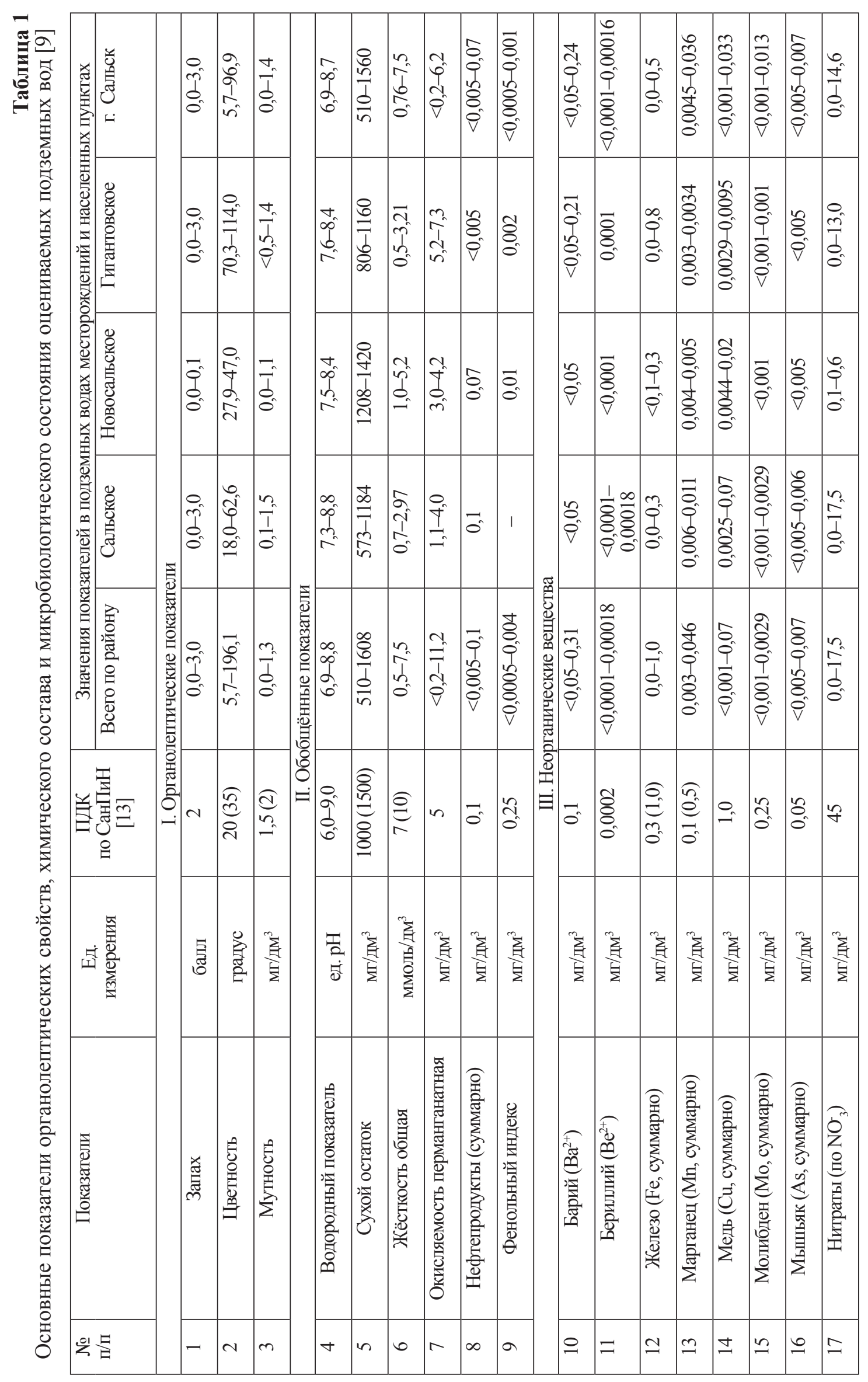

- УСПЕХИ СОВРЕМЕННОГО ЕСТЕСТВОЗНАНИЯ № 12, 2017 
تِ

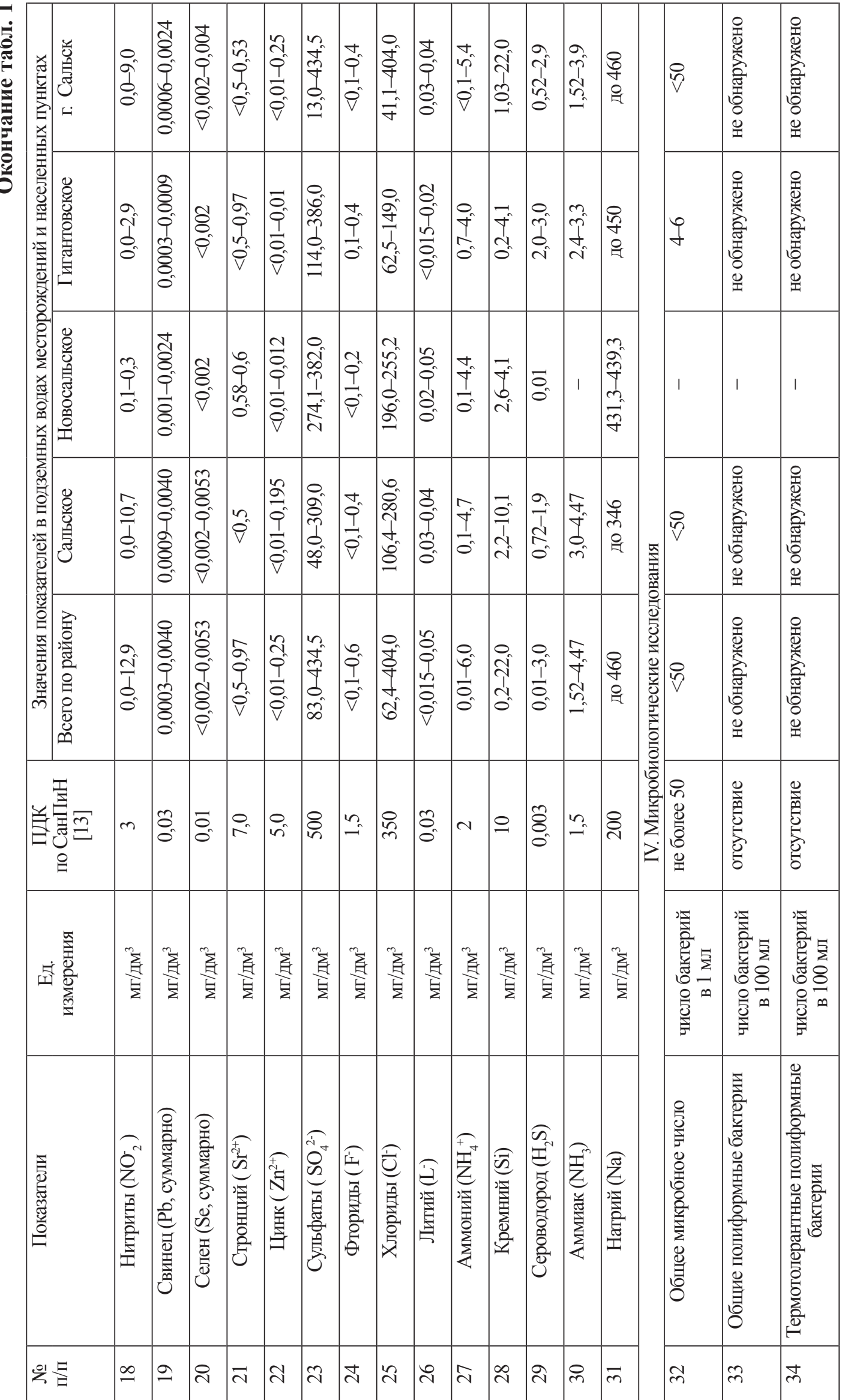


В пределах неогеновых отложений выделяются следующие водоносные комплексы и горизонты:

- подземные воды спорадического распространения азово-кубанской серии верхнего плиоцена $(N, a k)$;

- водоносный комплекс отложений понтического яруса нижнего плиоцена $(N, p)$;

- водоносный комплекс отложений сарматского яруса верхнего миоцена $\left(N_{l} s\right)$;

- водоносный горизонт нерасчлененных конкско-караганских отложений среднего миоцена $\left(N_{l} k r-k n\right)$;

- водоносный горизонт отложений караганского яруса среднего миоцена $\left(N_{l} k r\right)$.

\section{Материалы и методы исследования}

Гидрогеологическое обследование скважин действующих водозаборов исполнялось ГУП «Кубаньгеология» Краснодарского края с целью изучения условий эксплуатации подземных вод. Всего обследовано 129 скважин, из них повторно - 63 скважины [9].

1. Бурение шести гидрогеологических скважин осуществлялось роторным способом сплошным забоем буровым агрегатом 1БА-15В, диаметрами трехшарошечных долот 190 мм и 161 мм. Для определения гидрогеологических параметров конкскокараганского горизонта был создан опытный куст из трех скважин глубиной 180 м, вскрывших полностью конкско-караганские отложения. Три наблюдательные скважины были пройдены до проектной глубины 145 м. Они решили следующие задачи: вскрыли конкско-караганский водоносный горизонт на полную мощность, установили глубины его залегания и эффективную мощность водовмещающих пород. В дальнейшем скважины вошли в системную сеть мониторинга подземных вод, необходимого для построения гидродинамической модели и разработки долгосрочных прогнозов функционирования водозаборных сооружений Сальского района. Общий объем бурения составил 975 м.

2. Геофизические исследования, а именно метод кажущихся сопротивлений и потенциалов естественной поляризации пород (КС, ПС), а также гамма-каротаж выполнялись для подтверждения литологического разреза, предварительной оценки качества подземных вод и выбора интервалов установки фильтров.

3. Опытные гидрогеологические испытания проводились с целью получения данных для сравнительной характеристики фильтрационных свойств; анализа качества вод конкско-караганского водоносного горизонта; уточнения его гидрогеологических параметров на участке между Бровкинским водозабором и п. Гигант. Комплекс работ включал следующие методы: разглинизация скважин, пробные откачки, опытные кустовые откачки, остановка и пуск эксплуатационных скважин.

4. В процессе мониторинга подземных вод конско-караганского горизонта производились замеры уровней и температуры подземных вод во всех опорных режимных скважинах; прокачка скважин погружным электрическим насосом перед отбором проб воды для лабораторных анализов по определению их химического состава.
5. Опробование водоносного горизонта и лабораторное изучение физических свойств, химического состава подземных вод, заключения об их качестве проведены в соответствие с утвержденными стандартными методиками [10-13]. Всего исследовано 381 проба воды.

На основании полученных данных авторами выполнены расчеты: по проектированию нового водозабора, установлению его рентабельности; прогнозных ресурсов и эксплуатационных запасов для выделенного водоносного горизонта.

\section{Результаты исследования и их обсуждение}

Анализ гидродинамических параметров водоносных горизонтов, химического и микробиологического состава подземных вод позволил установить, что для централизованного хозяйственно-питьевого водоснабжения г. Сальска и других населенных пунктов наиболее перспективным остается конкско-караганский водоносный горизонт. В пределах района он развит повсеместно. Основная область питания находится на Ставропольском сводовом поднятии, а частичное пополнение баланса осуществляется в долине р. Западный Маныч, где происходит перетекание вод аллювиальноморских отложений.

Водовмещающими породами являются мелко- и тонкозернистые, местами глинистые, кварцевые пески и слабосцементированные, глинистые песчаники. Общая мощность этих отложений по району изменяется от 15 до 55 м. Кровля водовмещающих песков вскрывается на глубинах 75-225 м, в зависимости от рельефа местности и гипсометрической поверхности пород, которая фиксируется на абсолютных отметках от - 30 до -130 м, с общим погружением кровли в западном и юго-западном направлениях. По степени неоднородности фильтрационных свойств водовмещающих пород данный водоносный горизонт относится к однородным (удельные дебиты однотипно оборудованных скважин различаются не более чем в 5 раз). Коэффициенты фильтрации изменяются от 4,03 до $12,40 \mathrm{M} /$ сут, чаще - 5-7 м/сут; водопроводимость - от 100 до $400 \mathrm{~m}^{2} /$ сут, чаще - 150$250 \mathrm{~m}^{2} /$ сут. Повышенная водопроводимость 250-300 м²/сут отмечена в пределах зоны с максимальным водоотбором (х. Бровки) [9].

Пьезометрический уровень вод выделенного горизонта устанавливается на глубинах от 25 до 90 м (абсолютные отметки $-10,3$ м, -25,66 м). Дебиты скважин изменяются в больших пределах от 1,4 до 22,2 дм $3 /$ с при понижениях уровня воды соответственно на 25 и 50 м. Максимальные дебиты 10,4-22,2 дм³ с получены по 
эксплуатационным скважинам в г. Сальске и при групповых откачках на участках детальных разведок. В районе х. Бровки дебиты скважин составляют 14,0-18,5 дм³/c; на Новосальском месторождении подземных вод - 10,4-15,5 дм $3 / \mathrm{c}$; на Гигантовском месторождении - 9,6-13,1 дм³/с [9].

Воды конкско-караганского водоносного горизонта от пресных до весьма слабосолоноватых с сухим остатком от 0,51 до 1,61 г/дм³ , преобладают значения 0,91,4 г/дм ${ }^{3}$. По величине общей жёсткости воды преимущественно мягкие - 0,55,2 ммоль/дм³ ${ }^{3}$ По ионному составу воды смешанные хлоридно-сульфатно-гидрокарбонатные, сульфатно-хлоридно-гидрокарбонатные натриевые. По бактериологическим показателям соответствуют предъявляемым требованиям [12]. В табл. 1 приведены основные показатели органолептических свойств, химического состава и микробиологического состояния оцениваемых подземных вод. Качество подземных вод конкско-караганского водоносного горизонта отличается стабильностью и, как правило, во время эксплуатации сухой остаток почти не изменяется, о чем свидетельствует многолетний опыт добычи подземных вод этого водоносного горизонта на территории г. Сальска, на Бровкинском водозаборе [9].

Данные таблицы демонстрируют, что качество подземных вод горизонта по некоторым показателям не соответствует санитарным нормам [13]. Выявленные отклонения имеют постоянный характер

$$
\begin{gathered}
B=2 \times R_{\text {вл },} \\
R_{\text {вл }}=1,5 \times \sqrt{a \times t,} \\
q=\frac{\Delta H}{L}\left(\frac{\Delta h}{l}\right),
\end{gathered}
$$

где $R_{\text {вл }}$ - радиус влияния, м; $a$ - коэффициент пьезопроводности, м²/сут; $t$ - количество суток, принятое на расчетный срок эксплуатации водозабора (10000); $k$ - коэффициент фильтрации, м/сут; $m$ - мощность водоносного горизонта, м; I - напорный градиент, д.е.; разность напоров, м; $L$ - расстояние между точками, на которых фиксируются максимальная и минимальная величины напоров [14]. В ходе полевых испытаний были установлены следующие значения гидрогеологических параметров:

$-a-$ коэффициент пьезопроводности $=$ $=4,8 \times 10^{5} \mathrm{M}^{2} /$ сут;

$-k$ - коэффициент фильтрации $k_{c p}=6 \mathrm{~m} / \mathrm{cyт;}$

$-m-$ мощность водоносного горизонта $37,5 \mathrm{M}$;

- I- напорный градиент 0,001 д.е.;

$-\Delta H-$ разность напоров: $H_{1}=+10 \mathrm{~m}$; $H_{2}=+5 \mathrm{M}, I=0,001$ [15].

В итоге были получены величины: $R_{\text {вл }}=103,5$ тыс. м; $q=0,29 \mathrm{M}^{2} /$ сут, а прогнозные ресурсы подземных вод для выделенного водоносного горизонта составили $60000 \mathrm{~m}^{3} /$ сут.

Эксплуатационные запасы подземных вод по конкско-караганскому водоносному горизонту по категориям $\mathrm{A}+\mathrm{B}+\mathrm{C}_{1}$ приведены в табл. 2.

\begin{tabular}{|c|c|c|c|c|c|c|}
\hline \multirow[t]{2}{*}{$\begin{array}{l}\text { № } \\
\Pi / \Pi\end{array}$} & \multirow[t]{2}{*}{ Наименование месторождения } & \multirow{2}{*}{$\begin{array}{c}\text { Количество } \\
\text { водозаборных } \\
\text { скважин }\end{array}$} & \multicolumn{4}{|c|}{$\begin{array}{c}\text { Эксплуатационные запасы подземных вод, } \\
\text { тыс. } \text { м }^{3} \text { сут }\end{array}$} \\
\hline & & & Всего по «А + В + $\mathrm{C}_{1} »$ & $\mathrm{~A}$ & $\mathrm{~B}$ & $\mathrm{C}_{1}$ \\
\hline 1 & Сальское (Бровкинский водозабор) & 15 скв. & 12,5 & 12,5 & - & - \\
\hline 2 & Новосальское МПВ & 10 скв. & 8,0 & - & 8,0 & - \\
\hline 3 & Гигантовское МПВ & 5 скв. & 4,0 & - & 4,0 & - \\
\hline & Всего & 30 скв. & 24,5 & 12,5 & 12,0 & - \\
\hline
\end{tabular}

Таблица 2

Эксплуатационные запасы подземных вод по конкско-караганскому водоносному горизонту

и обусловлены особенностями вмещающих пород, а именно высокой концентрацией органических веществ (гумуса) [9].

Прогнозные ресурсы подземных вод рассчитывались по формуле

$$
P=B \times q,
$$

где $B$ - ширина перехватываемого потока, м; $q$ - погонный расход, $\mathrm{M}^{2} /$ сут;
Таким образом, эксплуатационные запасы подземных вод по категориям «A $+\mathrm{B}+\mathrm{C}_{1}$ » составляют 27,8 тыс. м $^{3}$ суутки и удовлетворяют заявленной потребности в воде г. Сальска $\left(20,5\right.$ тыс. м ${ }^{3} /$ сутки) и близлежащих населённых пунктов.

Одной из целей данной статьи является определение максимально возможной производительности проектируемого во- 
дозаборного сооружения, ввод которого более экономически рентабелен, чем реконструкция и расширение внешнего водоснабжения. При этом расчетная величины понижения уровня воды в скважинах

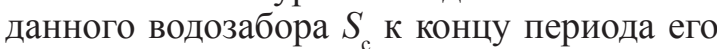
эксплуатации не должна превышать максимально допустимого в конкретных природных условиях понижения $S_{\text {доп }}$. При $S_{\text {с }} \leq S_{\text {доп }}$ производительность водозабора, а соответственно и эксплуатационные запасы считаются обеспеченными на принятый в расчетах срок [14]. Расчет производился по следующей формуле:

$$
\begin{gathered}
S_{\text {с }}=S_{\text {вдзб }}=\frac{Q_{\text {вдзб }}}{2 \times \pi \times k \times m} \times \ln \frac{1,5 \sqrt{a \times t}}{R_{0}}, \\
R_{0}=\sqrt{\frac{F}{\pi}},
\end{gathered}
$$

где $Q_{\text {вдзб }}-$ производительность водозабора, $\mathrm{м}^{3} /$ сут; $; F$ - площадь водозабора, м $^{2}$.

При расчетах дополнительно к приведенным ранее использовались следующие значения гидрогеологических параметров: $Q_{\text {вдзб }}=12500 \mathrm{~m}^{3} /$ сут; $F=180000 \mathrm{~m}^{2}$ [14]. Получены следующие значения: $R_{0} \approx 239,4$ м; $S_{\text {с }}=S_{\text {вдзб }}=34,4 \mathrm{м} ; S_{\text {доп }}=47$ м. Так как $S_{\text {с }}^{\text {с }}=S_{\text {вдзб }}^{\text {вдзб }}(34,4 \mathrm{м}) \leq S_{\text {доп }}^{\text {доп }}(47 \mathrm{м})$, то производительность водозабора, а соответственно и эксплуатационные запасы подземных вод рассматриваемого водоносного горизонта являются обеспеченными на принятый в расчетах срок.

\section{Выводы}

На основе сравнения всех гидродинамических характеристик изученных водоносных горизонтов четвертичных и неогеновых отложений установлено следующее.

1. Наиболее перспективным для централизованного хозяйственно-питьевого водоснабжения г. Сальска и близлежащих населенных пунктов остается конкско-караганский водоносный горизонт, обладающий нижеперечисленными особенностями:

- большая мощность водовмещающих пород, по району изменяется от 15 до 55 м;

- высокие дебиты скважин, максимальные значения составляют 10,4-22,2 дм³/c;

- высокие коэффициенты фильтрации (5-7 м/сут) и водопроводимости (150$250 \mathrm{M}^{2} /$ сут);

- отсутствие гидравлической связи горизонта с вышезалегающими сарматским и понтическим водоносными комплексами;

- наличие надежных водоупоров в подошве горизонта, представленного плотными глинами караганского горизонта мощностью от 8 до $76 \mathrm{M}$.

2. На основе произведенных расчетов можно сделать вывод о том, что рассчитанные эксплуатационные запасы подземных вод (27,8 тыс. м³/сут) при водопотреблении населения Сальского района 20,5 тыс. $\mathrm{M}^{3}$ ссут, обеспечиваются прогнозными ресурсами, рассчитанными для выделенного водоносного горизонта (60 тыс. м³/сут).

3. Полученные значения $S_{\text {с }}=S_{\text {вдзб }}(34,4$ м $) \leq$ $\leq S_{\text {доп }}(47$ м) показывают, что производительность проектируемого водозабора является рентабельной, обеспечивает водные ресурсы конско-канского горизонта на принятый в расчетах срок, а следовательно, сооружение водозабора полностью решает проблему хозяйственного водоснабжения Сальского района.

\section{Список литературы}

1. Об утверждении классификация запасов и прогнозных ресурсов питьевых, технических и минеральных подземных вод: приказ Министерства природных ресурсов РФ Приказ от 30 июля 2007 года № 195 //Собрание законодательства - 2004, № 26, Ст. 2669, 2006; № 25, Ст. 2723.

2. Тишаева О.Л. Отчет о результатах предварительной и детальной разведок месторождения подземных вод для водоснабжения п.г.т. Гигант Ростовской области / О.Л. Тишаева. - Ростов н/Д., 1972. - 126 с.

3. Прасолова А.М. и др. Отчет о результатах детальной разведки вод для хозяйственно-питьевого водоснабжения г. Сальска Ростовской области. - Ростов н/Д., 1975. - 138 с.

4. Геология СССР. - М.: Изд-во «Недра», 1970. - 548 с.

5. Сафронов И.Н. Геоморфология Северного Кавказа / И.Н. Сафронов. - Ростов н/Д.: Изд-во Ростовского ун-та, 1969. $-217 \mathrm{c}$

6. Харчук В.В., Тарасов М.Г., Скляренко В.В., Драчев Я.М. Подземные воды - основной источник хозяйственнопитьевого водоснабжения населенных пунктов Сальского района Ростовской области // Актуальные проблемы наук о Земле: тезисы докл. конф. студентов и молодых ученых с международным участием (Ростов-на-Дону, 14-15 окт. 2015.). - Ростов-н/Д., 2015. - С. 148-151.

7. Харчук В.В., Тарасов М.Г., Скляренко В.В., Драчев Я.М. Источники формирования ресурсов пресных подземных вод Сальского района Ростовской области // Актуальные проблемы наук о Земле: тезисы докл. конф. студентов и молодых ученых с международным участием. (Ростов-на-Дону, 14-15 окт. 2015.). - Ростов-н/Д., 2015. С. 151-154.

8. Гидрогеология СССР: сводный том, выпуск 5/ под ред. Г.Г. Скворцова. - М.: Изд-во «Недра», 1975. - 263 с.

9. Куцевалов А.Я. Отчёт по объекту: «Оценка эксплуатационных запасов подземных вод хозяйственно-питьевого назначения в пределах депрессионной воронки, вызванной работой сальских групповых водозаборов» (оценка запасов по состоянию на 01.01.2009 г.) / А.Я. Куцевалов. - Краснодар, 2010. - 665 c.

10. ГОСТ 189963-73. Вода Питьевая. Методы санитарно-бактериологического анализа. Контроль качества воды. Взамен ГОСТ 5215-50 и ГОСТ 5216-50; Введ. с 01.07.1974. М.: ФГУП «Стандартинформ», 2010. - 16 с.

11. ГОСТ 3351-74. Вода Питьевая. Методы определения вкуса, запаха, цветности и мутности. Контроль качества воды. - Взамен ГОСТ 3351-46; Введ. с 01.07.1975. - М.: ФГУП «Стандартинформ», 2010. - 8 с. 
12. ГОСТ Р 51309-99. Вода Питьевая. Определение содержания элементов методами атомной спектрометрии. Контроль качества воды. - М.: ФГУП «Стандартинформ», 2010. -23 c.

13. Санитарные правила и нормы: СанПиН 2.1.4.1074-01 Питьевая вода. Гигиенические требования к качеству воды централизованных систем питьевого водоснабжения. Контроль качества. - М.: Информационно-издательский центр Минздрава России, 2002. - 46 с.

14. Климентов П.П. Кононов В.М. Динамика подземных вод: учеб. для вузов. - 2-е изд. - М.: Высшая школа, 1985. $-384 \mathrm{c}$.

15. ГОСТ 23278-2014 Грунты. Методы полевых испытаний проницаемости. - Взамен ГОСТ 23278-78; Введ. 01.07.2015. - М.: ФГУП «Стандартинформ», 2015. - 40 с.

\section{References}

1. Ob utverzhdenii klassifikacija zapasov i prognoznyh resursov pitevyh, tehnicheskih i mineralnyh podzemnyh vod: prikaz Ministerstva prirodnyh resursov RF Prikaz ot 30 ijulja 2007 goda no. 195 // Sobranie zakonodatelstva 2004, no. 26, St. 2669, 2006; no. 25, St. 2723.

2. Tishaeva O.L. Otchet o rezultatah predvaritelnoj i detalnoj razvedok mestorozhdenija podzemnyh vod dlja vodosnabzhenija p.g.t. Gigant Rostovskoj oblasti / O.L. Tishaeva. Rostov n/D., 1972. $126 \mathrm{p}$.

3. Prasolova A.M. i dr. Otchet o rezultatah detalnoj razvedki vod dlja hozjajstvenno-pitevogo vodosnabzhenija g. Salska Rostovskoj oblasti. Rostov n/D., 1975. 138 p.

4. Geologija SSSR. M.: Izd-vo «Nedra», 1970. 548 p.

5. Safronov I.N. Geomorfologija Severnogo Kavkaza/ I.N. Safronov. Rostov n/D.: Izd-vo Rostovskogo un-ta, 1969. 217 p.

6. Harchuk V.V., Tarasov M.G., Skljarenko V.V., Drachev Ja.M. Podzemnye vody osnovnoj is-tochnik hozjajstvenno-pitevogo vodosnabzhenija naselennyh punktov Salskogo rajona Ro-stovskoj oblasti // Aktualnye problemy nauk o Zemle: tezisy dokl. konf. studentov i molodyh uchenyh s mezh- dunarodnym uchastiem (Rostov-na-Donu, 14-15 okt. 2015.). Rostov-n/D., 2015. pp. 148-151.

7. Harchuk V.V., Tarasov M.G., Skljarenko V.V., Drachev Ja.M. Istochniki formirovanija resursov presnyh podzemnyh vod Salskogo rajona Rostovskoj oblasti // Aktualnye pro-blemy nauk o Zemle: tezisy dokl. konf. studentov i molodyh uchenyh s mezhdunarodnym ucha-stiem. (Rostov-na-Donu, 14-15 okt. 2015.). Rostov-n/D., 2015. pp. 151-154.

8. Gidrogeologija SSSR: svodnyj tom, vypusk 5/ pod red. G.G. Skvorcova. M.: Izd-vo «Nedra», 1975. 263 p.

9. Kucevalov A.Ja. Otchjot po obektu: «Ocenka jekspluatacionnyh zapasov podzemnyh vod hozjajstvenno-pitevogo naznachenija $\mathrm{v}$ predelah depressionnoj voronki, vyzvannoj rabotoj salskih gruppovyh vodozaborov» (ocenka zapasov po sostojaniju na 01.01.2009 g.) / A.Ja. Ku-cevalov. Krasnodar, 2010. 665 p.

10. GOST 189963-73. Voda Pitevaja. Metody sanitarnobakteriologicheskogo analiza. Kon-trol kachestva vody. Vzamen GOST 5215-50 i GOST 5216-50; Vved. s 01.07.1974. M.: FGUP «Standartinform», 2010.16 p.

11. GOST 3351-74. Voda Pitevaja. Metody opredelenija vkusa, zapaha, cvetnosti i mutnosti. Kontrol kachestva vody. Vzamen GOST 3351-46; Vved. s 01.07.1975. M.: FGUP «Standar-tinform», 2010.8 p.

12. GOST R 51309-99. Voda Pitevaja. Opredelenie soderzhanija jelementov metodami atomnoj spektrometrii. Kontrol kachestva vody. M.: FGUP «Standartinform», 2010. 23 p.

13. Sanitarnye pravila i normy: SanPiN 2.1.4.1074-01 Pitevaja voda. Gigienicheskie tre-bovanija $\mathrm{k}$ kachestvu vody centralizovannyh sistem pitevogo vodosnabzhenija. Kontrol kachestva. M.: Informacionno-izdatelskij centr Minzdrava Rossii, 2002. 46 p.

14. Klimentov P.P. Kononov V.M. Dinamika podzemnyh vod: ucheb. dlja vuzov. 2-e izd. M.: Vysshaja shkola, 1985. $384 \mathrm{p}$.

15. GOST 23278-2014 Grunty. Metody polevyh ispytanij pronicaemosti. Vzamen GOST 23278-78; Vved. 01.07.2015. M.: FGUP «Standartinform», 2015. 40 p. 